\title{
LAS MARCAS Y LOS ELEMENTOS DE LA PERSONALIDAD: \\ ASPECTOS RELEVANTES PARA LA PROTECCIÓN DE LA IDENTIDAD Y EL PRESTIGIO DE PERSONAS NATURALES
}

\author{
Trademarks and Elements of Personality: \\ Relevant Aspects for The Protection of The Identity \\ and Prestige of Natural Personse
}

\author{
Gabriel Benites Arrieta \\ Universidad ESAN, Perú \\ https: / / orcid.org/0000-0002-4261-7231
}

\section{Resumen}

Muchos signos distintivos de productos y servicios que se ofrecen en el mercado están constituidos por términos que reproducen elementos de identificación de personas naturales. En algunos casos, se advierte que la decisión de compra es determinada por el mensaje que se asume con la identificación de la persona. Con este estudio se pretende desarrollar los aspectos jurídicamente relevantes desde la óptica del derecho de marcas que permitan solucionar posibles conflictos a partir de un signo constituido por un elemento asociado con la identidad o el prestigio de un tercero.

Palabras clave: derecho de marcas, derechos de la personalidad, afectación a la identidad, afectación al prestigio

\begin{abstract}
Many distinctive signs of products and services offered in the market are made up of terms that reproduce elements of identification of natural persons. In some cases, it is noted that the purchase decision is determined by the message that is assumed with the identification of the person. This study aims to develop the legally relevant aspects from the standpoint of trademark law that allow for settling possible conflicts based on a sign
\end{abstract}


made up of an element associated with the identity or prestige of a third party.

Keywords: trademark law, personality rights, affection on identity, affection on prestige

\section{Introducción}

La identidad es un derecho fundamental reconocido por la Constitución Política del Perú y resulta indispensable para individualizar a las personas y permitir su desarrollo en sociedad. Este derecho se materializa, por lo general, a través del nombre, lo cual no impide recurrir a otros elementos, como, por ejemplo, el seudónimo. Además, es posible desarrollar actividades comerciales incorporando algunas otras características de identificación, tales como el prestigio o el reconocimiento.

Sin embargo, los elementos con los que se ejerce el derecho a la identidad no siempre son suficientes por sí mismos para impedir que puedan ser incorporados en una marca. La legislación marcaria vigente en nuestro país establece un parámetro de protección al incluir una prohibición de registro cuya aplicación está condicionada al cumplimiento de requisitos, los cuales serán analizados en el desarrollo de este trabajo.

En ese sentido, se pretende explicar las dudas existentes en torno a la protección de los elementos de la personalidad frente a marcas que los contengan y dirimir las controversias que, a partir de este hecho, puedan existir.

\section{El derecho fundamental a la identidad}

El Tribunal Constitucional ha definido el derecho fundamental a la identidad -recogido en el primer numeral del artículo 2 de la Constitución Política del Estado- como «aquel que tiene todo individuo a ser reconocido estrictamente por lo que es y por el modo como es; es decir, a ser individualizado conforme a determinados rasgos distintivos, siendo algunos de ellos de carácter objetivo (nombres, seudónimos, registros, herencia genética, características corporales, etc.), y otros, de carácter subjetivo, los que se derivan del propio 
desarrollo y comportamiento personal (ideología, identidad cultural, valores, reputación, etc.)» ${ }^{1}$.

En correlato con el texto constitucional, el Código Civil, en su artículo 19, establece que toda persona tiene el derecho y el deber de llevar un nombre, el cual incluye los apellidos. Asimismo, el referido cuerpo de leyes dispone en su artículo 32 que el seudónimo, cuando adquiere la misma importancia que el nombre, goza de la misma protección jurídica dispensada a este.

Así, el derecho al nombre es una condición ineludible de toda persona humana que representa su principal medio de individualización. Su reconocimiento y protección se encuentran amparados en su incorporación como derecho fundamental.

Cabe indicar que el nombre se encuentra conformado por un prenombre y por un apellido ${ }^{2}$, por lo que a lo largo del presente trabajo se utilizará esta distinción para delimitar la referencia a un prenombre (nombre de pila) y a un nombre, el cual deberá entenderse como el conjunto de prenombres y apellidos.

A continuación, se determinarán los alcances de la protección jurídica sobre los elementos de la personalidad frente a su incorporación en una marca y cuáles son las condiciones para que estos elementos constituyan un derecho oponible.

\section{Elementos de identificación personal como marcas}

En el tráfico comercial se aprecian numerosos casos de marcas que utilizan elementos de identificación personal (principalmente nombres o seudónimos) de gente famosa con la finalidad de distinguir productos y servicios. El propósito es lograr una preferencia del consumidor a partir del conocimiento público de dichas personas. $\mathrm{Al}$ respecto, Botana Agra afirma lo siguiente:

... los empresarios eligen como marcas nombres de personas célebres o prestigiosas que por alguna circunstancia son susceptibles de asociar los productos o

1 Sentencia recaída en el Proceso 05829-2009-PA/TC (ver fundamento 2).

2 El Reglamento de Inscripciones del Registro Nacional de Identificación y Estado Civil, aprobado por el Decreto Supremo 015-98, establece en sus disposiciones generales (artículo 2) que se entenderá como nombre a los prenombres y los apellidos de la persona. 
servicios correspondientes con la persona cuyo nombre se pretende registrar como marca; se aspira así a que el respectivo producto o servicio se apropie de la celebridad o prestigio del que goza la persona titular del nombre empleado como marca ${ }^{3}$.

En ese mismo sentido, Flaquer Riutort, sostiene que:

Si la utilización del nombre y los apellidos propios como marca constituye un caso relativamente frecuente como consecuencia del legítimo deseo del empresario de individualizar sus productos o servicios mediante su propio nombre civil, son aún más frecuentes aquellas otras hipótesis en que se recurre al nombre o a los apellidos de un tercero que goza de una especial fama o reputación entre el público de los consumidores, ya que ello, lógicamente, puede acabar repercutiendo en una mayor aceptación del producto en el mercado ${ }^{4}$.

Siguiendo a la doctrina citada, se debe tener en consideración que este tipo de signos no solamente son percibidos por el consumidor como el nombre $\mathrm{u}$ otro elemento de identificación de una persona, sino también como indicadores de una procedencia empresarial, esto es, una marca.

Un claro ejemplo de lo afirmado puede notarse en el sector de la moda, donde el reconocimiento de que los consumidores han trasladado a aquellas prendas de vestir o accesorios «de diseñador», ha permitido a sus productores mantener un mercado cautivo y lograr que el consumidor entienda y acepte que es mayor el precio de una prenda o accesorio «de diseñador» frente a una prenda o accesorio producido a gran escala. Para ilustrar esto, basta con citar los casos de las marcas Pierre Cardin, Giorgio Armani o Christian Dior, que corresponden a nombres de personas naturales, quienes no nacieron con el nivel de reconocimiento que actualmente tienen; han logrado, sin embargo, que sobre el prestigio de sus nombres se levanten grandes corporaciones. Igual es el caso de Marriott, Gillette, Disney o Bosch, que son compañías de alcance mundial cuyas marcas están conformadas por los apellidos de sus fundadores.

El mercado peruano no ha sido ajeno a esta práctica, y existen marcas que han trascendido durante décadas, con lo cual han alcanzado importantes

3 Manuel Botana Agra, «El registro del nombre de un tercero como marca», en Actas de Derecho Industrial 1977 (Madrid: Montecorvo, S. A., 1978), 257.

4 Juan Flaquer Riutort, "Contribución al estudio de la marca patronímica», en Actas de Derecho Industrial n. ${ }^{\circ} 16$ 1995-1995 (Madrid: Marcial Pons, 1996), 256. 
niveles de participación en sus sectores, tales como D'Onofrio, Santiago Queirolo, Nicolini o Field.

Ahora bien, es posible definir una marca como el elemento que tiene la función de diferenciar los productos o servicios de un competidor de los del resto. Para que esto suceda, dicho elemento debe cumplir con el requisito de distintividad, característica necesaria para que los productos o servicios sean identificados por el público como provenientes de un origen empresarial determinado. Por ello, algunos elementos que presenten determinadas características, como resultar descriptivos, genéricos o engañosos en relación con los productos o servicios a los que se apliquen, no podrán constituirse como marca.

Entonces, si el objetivo es analizar cómo es que un nombre u otro elemento de la personalidad puede constituirse en marca, la primera prueba que se debe superar es el requisito de la distintividad; es decir, el elemento que se pretende registrar como marca debe contar con características suficientes que permitan a los consumidores asociarlo con un origen empresarial específico.

Si bien por un lado puede apreciarse el derecho fundamental a la identidad que comprende el uso del nombre $u$ otros elementos de identificación desde un plano civil, el análisis que se efectuará desde la óptica del derecho marcario no será el mismo. En esa línea, Botana Agra indica lo siguiente:

... al registrar como marca el nombre de una tercera persona, se quiere constituir sobre el mismo un derecho de exclusiva -el derecho de marca- que tropieza ostensiblemente con la naturaleza inalienable e irrenunciable del nombre de las personas. Porque al registrar el nombre como marca, éste queda sujeto a un régimen sustancialmente distinto del que regula el nombre como signo individualizador de las personas ${ }^{5}$.

Ahora, la pregunta que debe responderse es: ¿cuándo es distintivo un elemento de la personalidad? Para dar una respuesta, se necesita considerar que el análisis de distintividad es un examen en el que la autoridad determina si la marca puede resultar útil para distinguir los productos o servicios a los que pretende aplicarse; de este modo, dependerá del criterio de la autoridad verificar si resulta distintivo un signo conformado por un nombre $u$ otro elemento de identificación personal.

5 Botana Agra, «El registro del nombre de un tercero como marca», 258. 
Un ejemplo se advierte en la sentencia del Tribunal Supremo de Justicia de España del 28 de junio de 2006, referida al conflicto entre el signo solicitado Ana Domínguez y la marca registrada A. Domínguez, de titularidad de la empresa Adolfo Domínguez e hijos, S. L. Esta última se opuso invocando la prohibición relativa que dispone que no pueden registrarse los signos constituidos por el nombre, apellido $u$ otro medio que para la generalidad del público identifique a una persona distinta del solicitante; afirmaba que el otorgamiento del signo solicitado afectaría el conocimiento que Adolfo Domínguez ha ganado en el público. El argumento del referido tribunal puede verse en el párrafo que sigue:

Dado que en este caso el apellido "Domínguez" es común en España, su singularización mediante el nombre propio femenino "Ana" lo distingue suficientemente del nombre y apellidos utilizados por la sociedad recurrente ("Adolfo Domínguez e Hijos, S. L.") y de sus marcas aquí opuestas. Las diferencias, tal como son apreciadas por el tribunal de instancia, cuya apreciación hemos de respetar en casación, son suficientes como para justificar la recíproca compatibilidad de los signos.

Ese argumento también es recogido por López Gómez, quien afirma que:

... no recibirá el mismo tratamiento un apellido común o un apellido original o característico. Así, si se trata de un apellido muy común es obvio que no llamará de un modo especial la atención del consumidor medio, por lo que para que un empresario homónimo pudiera registrar su apellido como marca, a pesar de la existencia de una marca constituida por el mismo apellido, bastaría con añadir al apellido determinadas menciones distintivas que evitasen el riesgo de confusión ${ }^{6}$.

Igualmente, resultará de utilidad para comprender este escenario lo sucedido recientemente con Lionel Messi, uno de los futbolistas más reconocidos en la actualidad, quien, para lograr el registro de una marca conformada por su apellido (Messi), tuvo que enfrentar un litigio que llegó hasta el Tribunal

6 Jesús Ángel López Gómez, «Consideraciones sobre la homonimia en materia de signos distintivos», en Actas de Derecho Industrial 1978 (Madrid: Montecorvo, S. A., 1979), 465. 
de Justicia de la Unión Europea ${ }^{7}$. La solicitud de registro fue inicialmente denegada por considerarse que la denominación «Messi» es confundible con la marca «Massi», previamente registrada a favor de un tercero.

El criterio antes expuesto guarda concordancia con lo resuelto por el Tribunal de Justicia de la Comunidad Andina, el cual ha señalado que el nombre de una persona natural puede ser registrado como marca, siempre que, además de ser distintivo y no afectar la identidad o el prestigio de terceros, su uso en el mercado no genere confusión en el público .

Ruipérez de Azcárate ahonda en este asunto al citar la Sentencia del Tribunal de Justicia de la Unión Europea recaída en el caso C-404/02, la cual precisa que:

Del mismo modo que un término del lenguaje habitual, un apellido corriente puede cumplir la función de origen de la marca y ser, por lo tanto, distintivo para los productos o los servicios de que se trate, cuando no se enfrente a un motivo de denegación del registro que no sea el establecido en el artículo 3, apartado 1, letra b), de la Directiva 89/104 y que, por ejemplo, puede basarse en el carácter genérico o descriptivo de la marca, o bien, la existencia de un derecho anterior?

Vale referir que, bajo otro punto de vista, los tribunales británicos han analizado la distintividad del nombre de una persona famosa a partir de la posibilidad de que este resulte suficiente para identificar un origen empresarial, independientemente de la fama o prestigio que transmita ${ }^{10}$. Al respecto,

7 Sentencia del 17 de septiembre de 2020, recaída en el expediente en el que se tramitaron los asuntos acumulados C-449/18 P y C-474/18 P.

8 Pueden revisarse las interpretaciones prejudiciales emitidas en los procesos 219-IP-017, 468IP-2018 y 678-IP-2018.

9 Clara Ruipérez de Azcárate, El carácter distintivo de las marcas (Madrid: Reus, S. A., 2008), 93.

10 Torremans comenta el caso Elvis Presley Enterprises Inc. v. Sid Shaw Elvisly Yours [1997], en el que la Sala de Cancillería del Tribunal Superior de Justicia de Inglaterra determinó que la distintividad significa que la marca debe permitir que el consumidor pueda distinguir los productos o servicios de similares productos o servicios de otros competidores. Bajo ese punto de vista el uso de los nombres "Elvis" y "Elvis Presley" no permiten que el consumidor identifique una indicación específica de origen empresarial. De acuerdo con ello, la referida corte determinó que la mayoría de la gente compraría el producto porque tenía el nombre de la celebridad y no se preocuparía por su origen. Este fue el fundamento para que se deniegue el registro de marcas que contenían las denominaciones Elvis A. Presley, Elvis Presley y Elvis. En: Paul Torremans, Intellectual Property Law, 8. ${ }^{a}$ ed. (Oxford: Oxford University Press, 2016), 659-661. 
Martín Villarejo comenta que «a diferencia de otros países de corte anglosajón, la ley británica no ofrece un sistema particular de protección de nombres más allá del que puedan tener reconocido como marcas (sic)» ${ }^{11}$.

En suma, téngase en cuenta que todas las solicitudes de registro de marca están sujetas a un examen de registrabilidad en el que se determinará el cumplimiento de los requisitos legales para su concesión, entre los cuales se encuentra la no afectación a derechos marcarios previos de terceros.

A continuación, se procederá con el análisis del contenido de la prohibición, con el fin de explicar adecuadamente sus condiciones de aplicación y cuáles son los alcances que puede tener en un procedimiento referido a un derecho de marca.

\section{La prohibición de registrar como marcas los signos que afecten la identidad o el prestigio de terceros}

El inciso e) del artículo 136 de la Decisión 486 de la Comunidad Andina, Régimen Común sobre Propiedad Industrial (en adelante, «Decisión 486»), dispone que no podrán registrarse como marcas aquellos signos cuyo uso en el comercio afectará indebidamente el derecho de un tercero, en particular cuando afecten la identidad o prestigio de personas naturales, en especial, cuando se trate del nombre, apellido, firma, título, hipocorístico, seudónimo, imagen, retrato o caricatura ${ }^{12}$ de una persona distinta del solicitante o identificada por

11 Abel Martín Villarejo, «Singularidades subjetivas en relación con los artistas. Las interpretaciones bajo seudónimo. Derecho español, cubano y comparado», en Obras inéditas, anónimas, seudónimas, póstumas y huérfanas, ed. Eduardo Gómez Serrano y otros (Madrid: Editorial Reus S.A., 2014), 199-200.

12 La Real Academia Española y la Asociación de Academias de la Lengua Española otorgan a cada una de las palabras los siguientes significados.

- Nombre.- Nombre que se da a la criatura cuando se bautiza o el que le adjudica por elección para identificarla junto a los apellidos.

- Apellido.- Nombre de familia con que se distinguen las personas; p. ej., Fernández, Guzmán.

- Firma.- Rasgo o conjunto de rasgos, realizados siempre de la misma manera, que identifica a una persona y sustituyen a su nombre y apellidos para aprobar o dar autenticidad a un documento.

- Título.- Renombre o distintivo con que se conoce a alguien por sus cualidades o sus acciones.

- Hipocorístico.- Dicho de un nombre: Que, en forma diminuta abreviada o infantil, se usa como designación cariñosa, familiar o eufemística; p. ej., Pepe, Charo.

- Seudónimo.- Nombre utilizado por un artista en sus actividades, en vez del suyo propio. 
el sector pertinente del público como una persona distinta del solicitante ${ }^{13}$.

Esta disposición es la que regula la posibilidad de impedir el registro de marcas que contengan elementos de identificación de personas naturales.

Ahora, frente a la pregunta de cómo es posible que puedan registrarse marcas conformadas por elementos que identifican a terceros, el mismo inciso e) del artículo 136 de la Decisión 486 precisa que para tal fin deberá acreditarse el consentimiento de la persona en cuestión o, si hubiese fallecido, el de quienes hayan sido declarados sus herederos. Asimismo, el inciso e) del artículo 50 del Decreto Legislativo 1075, que aprueba Disposiciones Complementarias a la Decisión 486, establece que la solicitud de registro deberá comprender las autorizaciones requeridas a efectos de evitar que el signo solicitado se encuentre incurso en una prohibición de registro; incorpora, de esta manera, el requisito de acreditar el consentimiento de la persona titular de los elementos que la identifican o de sus herederos. Entonces, la presentación de la autorización es el filtro que determinará si la autoridad procederá a la evaluación de si un signo se encuentra incurso en la prohibición del inciso e) del artículo 136 de la Decisión 486, la cual —como podrá apreciarse en la jurisprudencia que se expondrá en los párrafos siguientes - solo será relevante cuando la autoridad advierta una afectación a la identidad o prestigio de una persona natural.

Antes de analizar las condiciones para oponer el derecho sobre los elementos de identificación, téngase en cuenta que el supuesto estudiado corresponde a una causal de denegatoria de acceso al registro de propiedad industrial y no a una acción que busque reparar la afectación a la identidad

- Imagen.- Figura, representación, semejanza y apariencia de algo.

- Retrato.- Pintura o efigie principalmente de una persona.

- Caricatura.- Dibujo satírico en que se deforman las facciones y el aspecto de alguien. Obra de arte que ridiculiza o toma en broma el modelo que tiene por objeto.

Información obtenida de www.rae.es.

13 El texto completo de la prohibición es el siguiente:

Artículo 136.- No podrán registrarse como marcas aquellos signos cuyo uso en el comercio afectará indebidamente un derecho de tercero, en particular cuando: [...]

e) consistan en un signo que afecte la identidad o prestigio de personas jurídicas con o sin fines de lucro, o personas naturales, en especial, tratándose del nombre, apellido, firma, título, hipocorístico, seudónimo, imagen, retrato o caricatura de una persona distinta del solicitante o identificada por el sector pertinente del público como una persona distinta del solicitante, salvo que se acredite el consentimiento de esa persona o, si hubiese fallecido, el de quienes fueran declarados sus herederos... 
personal, para lo cual quedan reservadas las disposiciones contempladas por los artículos 26 y 28 del Código Civil ${ }^{14}$.

Asimismo, se debe considerar que, para registrar un nombre o algún otro elemento de identificación personal como marca, deben cumplirse los mismos requisitos establecidos para cualquier otra marca; esto es, verificar lo dispuesto por el artículo 134 de la Decisión $486^{15}$ y que no se incurra en alguna prohibición de registro ${ }^{16}$.

Como presupuesto inicial, debe indicarse que en el Perú no es suficiente ser identificado con un nombre, apellido, seudónimo, título, hipocorístico o elemento gráfico para lograr la protección jurídica de dicho elemento bajo la legislación marcaria. Por este motivo, la homonimia o una similitud en los datos de identificación no serán determinantes para invocarlas como fundamento de oposición o como un mejor derecho para acceder al registro de una marca.

López Gómez expone una sentencia del Tribunal de Gran Instancia de París, a través de la cual se resolvió un caso en el que se discutía si la inclusión del apellido Picasso en una marca requería una autorización y, si era así, quién debía emitirla ${ }^{17}$. El Tribunal determinó que la cesión de un nombre para constituir una marca no es válida sino en la medida en que su titular ha adquirido notoriedad personal de tal naturaleza que justifique la cesión de su apellido para un uso comercial; de esa forma, la cesión presentada por el solicitante, ante la falta de notoriedad del emisor, no puede ser tomada en cuenta como una autorización de uso de apellido válida ${ }^{18}$.

14 Defensa del derecho al nombre

Artículo 26.- Toda persona tiene derecho a exigir que se le designe por su nombre. Cuando se vulnere este derecho puede pedirse la cesación del hecho violatorio y la indemnización que corresponda.

Indemnización por usurpación de nombre

Artículo 28.- Nadie puede usar nombre que no le corresponde. El que es perjudicado por la usurpación de su nombre tiene acción para hacerla cesar y obtener la indemnización que corresponda.

15 Artículo 134.- A efectos de este régimen constituirá marca cualquier signo que sea apto para distinguir productos o servicios en el mercado. Podrán registrarse como marcas los signos susceptibles de representación gráfica. La naturaleza del producto o servicio al cual se ha de aplicar una marca en ningún caso será obstáculo para su registro. (...)

16 Las prohibiciones de registro se encuentran en los artículos 135 y 136 de la Decisión 486.

17 El solicitante había obtenido la autorización de D. Jaime Picasso-Marsal para utilizar el apellido Picasso como marca. Paloma Ruiz-Picasso, hija del reconocido pintor español Pablo Picasso, formuló oposición.

18 Jesús Ángel López Gómez, «En torno a la autorización requerida para el empleo del apellido 
En el análisis efectuado por la Sala Especializada en Propiedad Intelectual del Indecopi (en adelante, la Sala Especializada en Propiedad Intelectual) en la Resolución 2372-2010/TPI-INDECOPI, se descartó la protección de los apellidos de las opositoras, los cuales coincidían con los elementos incorporados en el signo solicitado («Prado Rey Ternos... Clase en el vestir!» y logotipo, para la clase 25 de la Clasificación de Niza), ya que a través de estos no era posible asociar a una persona en particular. Dicha sala argumentó lo siguiente:

En el presente caso, la denominación PRADO REY, según alega la solicitante, constituye la unión de su primer apellido (lo cual se verifica de la copia del DNI que adjuntó en su escrito de fecha 28 de mayo de 2010 (obrante a foja 57) con la denominación REY.

Por otro lado, según consta en las copias de las consultas en línea efectuadas en la página del RENIEC obrantes a fojas 67 y 68 , el primer y segundo apellido de las opositoras se encuentran constituidos por las denominaciones PRADO y REY, respectivamente.

Asimismo, la Sala conviene en precisar que no es el propósito de la norma impedir el registro de marcas compuestas por un apellido originario de cualquier país, tal supuesto no se encuentra contemplado como tal en la Ley. En efecto, la prohibición está referida a nombres completos o apellidos que los consumidores del país puedan asociar con una persona determinada.

No obstante lo anterior, revisado el DNI presentado por el solicitante así como las impresiones de la página web de la RENIEC que obran en autos, la Sala considera que no se ha logrado acreditar que los apellidos PRADO REY sean identificados directamente por la generalidad del público consumidor con un personaje determinado, toda vez que si bien para el consumidor peruano las denominaciones PRADO y REY podrían ser asociadas con dos apellidos, dicha asociación no se encontraría referida a una persona en particular ${ }^{19}$.

de un tercero como marca (caso Picasso). Comentario a la sentencia del Tribunal Supremo (Sala Tercera) de 18 de junio de 1985», en Actas de Derecho Industrial 1989-1990 (Madrid: Colegio Universitario de Estudios Financieros, Consejo Superior Bancario, 1990), 158-159.

19 El Registro Nacional de Identificación y Estado Civil (Reniec) es el organismo autónomo peruano encargado de organizar y mantener el registro único de identificación de las personas naturales e inscribir los hechos y actos relativos a su capacidad y estado civil. (artículo 2 de la Ley 26497, Ley Orgánica del Registro Nacional de Identificación y Estado Civil) 
Para finalizar, cabe señalar que la jurisprudencia nacional ha sido uniforme en afirmar que los requisitos necesarios para que se aplique la prohibición de registro materia del presente trabajo ${ }^{20}$ son:

a) Que el signo cuestionado contenga un elemento que corresponda a una persona distinta del solicitante o que dichos elementos permitan al sector pertinente identificar a una persona distinta del solicitante.

b) Que dicho signo afecte la identidad o prestigio de la persona.

De acuerdo con lo expuesto, queda claro que la afectación al derecho sobre un elemento de identificación personal puede motivar la denegatoria de un registro de marca, siempre que concurran los requisitos antes indicados, los cuales serán explicados en los párrafos siguientes.

\section{La afectación debe recaer en una persona distinta del solicitante o identificada por el sector pertinente del público como una persona distinta del solicitante}

Cuando la prohibición diferencia entre una persona distinta del solicitante o identificada como tal por el sector pertinente del público, se refiere, en primer lugar, al supuesto de que efectivamente se trate de una persona distinta, es decir, se involucre a un tercero a través del uso de un elemento que permita identificarlo correcta y plenamente. En segundo lugar, se aprecia el supuesto en el que algunas personas no son identificadas con sus nombres reales, ya que usan nombres ficticios para desarrollar sus actividades y, en algunos casos, debido a su fama, el público las identifica con el nombre ficticio sin llegar a conocer el nombre verdadero ${ }^{21}$. Este es el caso de los seudónimos.

Así, para el análisis del segundo supuesto, deberá verificarse el nivel de conocimiento del seudónimo $\mathrm{u}$ otro elemento de identificación de la persona en el sector en el que desarrolla las actividades que le permitieron alcanzar fama y reconocimiento. Botana Agra comenta que cuando el nombre de un tercero que intenta registrarse como marca no identifica para la generalidad del público al titular del nombre de manera espontánea, directa e inmediata,

20 Puede verse las resoluciones 2858-2016/TPI-INDECOPI, 2173-2018/TPI-INDECOPI y 25152018/TPI-INDECOPI.

21 Pueden verse los casos de Bruno Mars (Peter Gene Hernández), Vin Diesel (Mark Sinclair Vincent), Elton John (Reginald Kenneth Dwight) o Woopy Goldberg (Caryn Elaine Johnson). 
ese nombre puede ser registrado como marca sin necesidad de previa autorización, al margen de cualquier consideración del nombre como derecho de la personalidad $^{22}$.

Fernández-Nóvoa menciona que el requisito básico de esta prohibición es la notoriedad o renombre de la persona cuyo signo identificador se solicita como marca. La prohibición será aplicable, por ejemplo, cuando, a pesar de coincidir con el nombre o el apellido del solicitante, el signo solicitado como marca evoca ante el público en general a un renombrado escritor, un celebérrimo pintor, un famoso actor o deportista, etc. ${ }^{23}$. Por su parte, Otamendi sostiene que nadie tiene por qué utilizar el nombre de otro ni su apellido, cuando pueda establecerse, debido a diversas circunstancias que se resumen en la notoriedad, que ese apellido es atribuible a un individuo o a una familia que lo lleve ${ }^{24}$.

Existen muchas actividades cuya trascendencia publicitaria se restringe a las personas involucradas en su ejercicio. Por ejemplo, existen algunos deportes que, si bien no tienen una práctica extendida, involucran a una comunidad de personas que lo practican. En efecto, en el Perú, deportes como el hockey o el sóftbol no reciben el mismo nivel de atención que el fútbol o el vóley; sin embargo, estas disciplinas cuentan con federaciones que les permiten participar en diversos eventos deportivos. Así, el hockey o el sóftbol cuentan con selecciones nacionales que reúnen a los mejores exponentes $\mathrm{y}$, dentro de este grupo selecto, habrá quienes destacan, gracias a lo cual logran un reconocimiento especial que los conducirá al prestigio.

De ese modo, en la comunidad de consumidores de artículos deportivos de hockey o sóftbol, los mejores exponentes tendrán un reconocimiento especial; en cambio, los elementos de identificación de tales deportistas pasarán desapercibidos en sectores distintos, como, por ejemplo, en las industrias de pinturas o telas.

La Resolución 2018-2014/CSD-INDECOPI contiene un análisis en el cual la Comisión de Signos Distintivos del Indecopi (en adelante, «la Comisión de Signos Distintivos»), al evaluar la acción de nulidad iniciada por Víctor Manuel Camacho Weberbauer contra el registro de una marca conformada por la

22 Botana Agra, «El registro del nombre de un tercero como marca», 272.

23 Carlos Fernández-Nóvoa, Tratado sobre Derecho de marcas, 2. ${ }^{a}$ ed. (Madrid: Marcial Pons, 2004), 251.

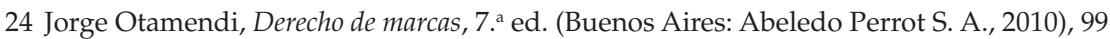


denominación «Weberbauer Schule», por haber sido otorgada sin contar con la autorización de los herederos del científico alemán Augusto Weberbauer, determinó, respecto de los medios probatorios del accionante, que:

... si bien están destinados a dar a conocer la vida del científico alemán AUGUSTO WEBERBAUER, así como a sus investigaciones en el ámbito de la botánica, tales documentos no desvirtúan por mérito propio los argumentos en que se basó la resolución recurrida, ello en atención a que con dichos documentos, el recurrente no ha demostrado que los usuarios de los servicios de la clase 41 de la Clasificación Internacional, logren asociar la denominación WEBERBAUER (que forma parte de la marca cuya nulidad se pretende) con la vida y persona del científico alemán AUGUSTO WEBERBAUER.

Otro caso con un supuesto de esta naturaleza puede apreciarse en la Resolución 0356-2010/TPI-INDECOPI, emitida por la Sala Especializada en Propiedad Intelectual, que, al analizar el asunto de una marca que contenía la denominación «Sir Benni Miles Clothing» para distinguir prendas de vestir, precisó lo siguiente:

... el hipocorístico SIR BENNI MILES será reconocido en el ámbito del diseño de modas y prendas de vestir nacional e internacional, por lo que el público consumidor del sector pertinente asociará el signo solicitado SIR BENNI MILES para prendas de vestir en general, de la clase 25 de la Nomenclatura Oficial, dado que se trata de una persona reconocida en el ámbito de las prendas de vestir, frente a los cuales el nombre de SIR BENNI MILES podría transmitir a los consumidores que la idea de que dichos productos se encuentran elaborados por el referido diseñador ${ }^{25}$.

Como puede verse en los casos expuestos, el signo analizado deberá contener información suficiente que permita al público individualizar a la persona afectada. Además, en ocasiones es suficiente el prenombre o el apellido de una persona para identificarla indubitablemente, algo que la coyuntura vigente puede contribuir a que suceda. Por ejemplo, será suficiente referir a Ricardo Gareca para que la gran mayoría del público consumidor de artículos deportivos o usuario de actividades deportivas asuma indubitablemente que se trata del director técnico actual de la selección peruana de fútbol; es más,

25 Previamente, la sala había determinado que el diseñador Aaron Benjamin Miles es conocido como «Sir Benni Miles». 
podría afirmarse que solamente el apellido Gareca será suficiente para individualizar al director técnico mencionado; siendo así, no se necesitará citar su nombre completo (Ricardo Alberto Gareca Nardi). Lo mismo no sucede, sin embargo, si solo se usa el prenombre Ricardo, el cual, al ser común, no identifica por sí mismo a una persona en concreto.

Si bien hay ciertos casos en los que será posible individualizar plenamente a una persona solamente con un prenombre, estos se reservan a quienes cuentan con niveles muy elevados de fama, en los que su alcance publicitario sobrepasa al sector pertinente de sus actividades.

Lo afirmado puede verse en la Resolución 2515-2018/TPI-INDECOPI, mediante la cual la Sala Especializada en Propiedad Intelectual, al analizar el prestigio del chef Gastón Acurio, señaló lo siguiente:

... a criterio de la Sala, el nombre "Gastón" del conocido chef Gastón Acurio, goza de gran reconocimiento y prestigio tanto a nivel nacional como internacional, al ser un importante chef y empresario peruano a quien se le atribuye el crecimiento y posicionamiento a nivel mundial de la gastronomía peruana. En ese sentido, se advierte que no sólo el público del sector pertinente de restauración, sino que el público en general asocia de manera inequívoca el nombre "Gastón" con la persona del conocido chef, debido a que es extensamente reconocido por la importante labor que ha realizado en el crecimiento y expansión de la gastronomía peruana, habiendo sido inclusive merecedor de diversos reconocimientos y premios de importante relevancia.

Un análisis de esta naturaleza, pero con una conclusión distinta, aparece en la Resolución 0632-2015/CSD-INDECOPI, emitida por la Comisión de Signos Distintivos. La referida autoridad evaluó si la denominación «Marilyn» era suficiente para afectar la identidad o prestigio de Norma Jeane Mortenson, conocida mundialmente como Marilyn Monroe. En la citada resolución se afirmó que:

En el presente caso, se advierte que si bien el signo solicitado presenta en su conformación la denominación MARILYN, la cual forma parte del seudónimo con el que se hizo conocida la actriz Norma Jeane Mortenson, cabe indicar que su sola presencia en el signo no afecta la identidad de quien en vida fue la referida actriz, toda vez que la denominación MARILYN tan solo constituye un nombre de pila bajo el cual no se identifica o se individualiza a persona alguna, ni tampoco a Nor- 
ma Jeane Mortenson, la cual fue conocida por su seudónimo completo (MARILYN MONROE) y no por una parte del mismo.

Igualmente, resulta pertinente referir el criterio de la Sala Especializada en Propiedad Intelectual adoptado en la Resolución 2073-2010/TPI-INDECOPI, en la cual consideró que el conocimiento de un elemento de identificación personal puede llegar a ser un hecho público y generalizado y que, de esa manera, no requiere la presentación de medios probatorios. Este criterio corresponde al análisis de la denominación «Pelé», que es el seudónimo del exfutbolista brasileño Edson Arantes Do Nascimento. Dicha sala motivó su pronunciamiento con el argumento que se reproduce a continuación:

En el caso concreto, es un hecho evidente, público y de conocimiento generalizado que la denominación PELÉ corresponde al seudónimo del exfutbolista brasileño Edson Arantes Do Nascimiento, por lo que tal circunstancia no requiere de la presentación de medios probatorios (...).

El seudónimo PELÉ es identificado por la generalidad del público nacional de manera espontánea, directa e inmediata con un personaje determinado, así como por parte del sector pertinente (que en el presente caso es el público consumidor de los productos de la clase 28 de la Nomenclatura Oficial).

Finalmente, debe tenerse en cuenta que en un mercado globalizado como el actual, en el cual la tecnología prácticamente ha eliminado las fronteras entre países, resulta habitual que muchas personas alcancen en corto tiempo una fama extendida internacionalmente, por lo que no será extraño encontrarnos con nombres extranjeros en diferentes idiomas. Para estos casos, deberá acreditarse que el elemento de identificación es asociado en forma indubitable por el público nacional con la persona extranjera, lo que permitirá analizar la posible afectación a la identidad o el prestigio de dicha persona ${ }^{26}$.

Lo anterior explica el primer requisito que debe concurrir para aplicar la prohibición: identificar plenamente a la persona afectada. Ello, sin embargo,

26 En la Resolución 3543-2016/TPI-INDECOPI, la Sala Especializada en Propiedad Intelectual precisó que la autorización se exigirá tan solo si el nombre es identificado por la generalidad del público nacional de manera espontánea, directa e inmediata con un personaje determinado distinto del solicitante y que, además, dicho nombre goce de un reconocimiento y prestigio en el país donde se invoca la protección. 
no es suficiente, puesto que resulta indispensable que el signo que se cuestiona transgreda la identidad o el prestigio de la persona en cuestión, lo cual será analizado a continuación.

\section{Afectación a la identidad}

Como se afirmó al inicio de este trabajo, la identidad resulta indispensable para la vida de una persona, puesto que le permite una individualización en la sociedad y, por tal relevancia, nuestro ordenamiento legal ha reconocido este derecho a nivel constitucional. De esa manera, las preguntas por responder en este punto son: ¿cuándo se puede apreciar una afectación de la identidad? y ¿cómo esa afectación a la identidad resulta cuestionable desde el punto de vista marcario?

Para iniciar la respuesta, corresponde citar al Tribunal Constitucional. Este ha establecido que, cuando una persona invoca su identidad, en principio lo hace para que se la distinga frente a otras. Aun cuando a menudo tal distinción pueda percibirse con suma facilidad a partir de datos tan elementales como el nombre ${ }^{27}$. Con ello se puede afirmar que la aplicación de la afectación a la identidad deberá involucrar la existencia de un signo que viole o impida que una persona pueda individualizarse frente a los demás o que se afecte esta individualización.

Fernández Sessarego define la identidad personal precisando lo siguiente:

La identidad es el conjunto de datos biológicos y de atributos y características que, dentro de la igualdad del género humano, permiten distinguir indubitablemente a una persona de todas las demás. Es decir, la identidad es "ser el que soy y no otro» o, en otros términos, "ser uno mismo y no otro".

Si se inquiere por la identidad de una persona que discurre en una reunión social o simplemente camina por la calle, lo que primero se pone en evidencia son sus caracteres somáticos tales como su estatura, su sexo o el color de su pigmentación. Pero, obviamente, ello es insuficiente para identificar a dicho sujeto. Por lo demás, dichos caracteres somáticos se hacen patentes ante una simple observación. Sin embargo, el inquirente, por lo general, quiere saber más sobre la

27 Sentencia recaída en el Proceso 2273-2005-PHC/TC (ver fundamento 23). 
identidad del ser humano que tiene ante sí por lo que pregunta por su ocupación, su ubicación social, sus creencias de todo tipo ${ }^{28}$.

Asimismo, el referido autor establece que la identidad personal se divide en dos aspectos: el estático y el dinámico. El aspecto estático involucra la información genética, que es la que biológicamente individualiza a la persona y permite distinguirla entre todas las demás; este aspecto es invariable. Por su parte, el aspecto dinámico, a diferencia del estático, se sustenta en cuestiones que pueden variar con el tiempo y que involucran creencias, culturas, ideologías, costumbres, entre otros elementos que, al igual que el aspecto estático, moldean la personalidad ${ }^{29}$.

Con relación a la lesión a la identidad personal, el citado autor señala que:

¿Cómo se lesiona la identidad personal? A juzgar por lo hasta aquí expuesto, ello acontece cuando, de algún modo y en diversa medida, se atenta contra la "verdad personal" que es, como se ha expresado, el interés existencial protegido por este específico derecho. Se agravia la identidad personal, de modo genérico, desnaturalizando, falseando, desvirtuando, alterando, distorsionando, ocultando dicha "verdad". Es decir, imputando al ser humano atributos, características, conductas o ideas que no le pertenecen, que no integran su "verdad" personal o negándole aquellas que le son propias ${ }^{30}$.

La intención de este trabajo no es realizar un análisis de la teoría del derecho a la identidad personal, pero este resumido extracto de doctrina muestra lo complejo que puede resultar su comprensión cabal, lo cual, no obstante, es indispensable para determinar sus alcances y así analizar su afectación a través de un signo distintivo.

Ahora bien, para ejemplificar algunas situaciones en las que pueda analizarse el supuesto de que un signo distintivo contiene un elemento que afecte la identidad personal, tómese en consideración los casos de una persona con una opinión contundente sobre un determinado campo de estudio o el de algún activista social. Así, podría encontrarse la caricatura de un personaje político que promueve la abstinencia sexual como método para impedir la

28 Carlos Fernández Sessarego, «Daño a la identidad personal», Themis 36 (1997): 248.

29 Carlos Fernández Sessarego, «Daño a la identidad personal».

30 Carlos Fernández Sessarego, «Daño a la identidad personal». 
propagación de enfermedades venéreas, aplicada a una marca que pretende distinguir pastillas anticonceptivas; también resultaría pertinente el uso del nombre de una reconocida dirigente de una comunidad vegana para distinguir carne de res.

Entonces, un factor determinante para evaluar la afectación a la identidad es el tipo de producto o servicio al que se aplica el signo que incluye los elementos de identificación de una persona, ya que serán estos los que determinen el mensaje que el consumidor asociará con la identidad de este personaje. El respaldo a esta afirmación puede encontrase en la jurisprudencia que se cita en los siguientes párrafos.

En la Resolución 0166-2019/TPI-INDECOPI puede verse un análisis realizado por la Sala Especializada en Propiedad Intelectual que generó la denegatoria del registro de la marca «Don Cucho» (para distinguir productos alimenticios y bebidas exclusivamente para animales) por afectar la identidad de Luis Armando La Rosa Cabizza. Dicho análisis se reproduce a continuación:

$\mathrm{Al}$ respecto, es conveniente señalar que el apelativo DON CUCHO se vincula de manera inmediata al nombre del opositor, Luis Armando La Rosa Cabizza, quién se dedica al rubro gastronómico, siendo dicha persona una distinta a la solicitante, Molitalia S. A. Asimismo, si bien se ha efectuado una limitación de productos a distinguir con el signo solicitado, a consideración de la Sala, persiste la afectación a su identidad, toda vez que el sector pertinente, asumirá que el señor Luis Armando La Rosa Cabizza ha incursionado en el sector de alimentos y bebidas para animales, lo cual no corresponde a la realidad.

En la decisión adoptada en la Resolución 3543-2016/TPI-INDECOPI, la Sala Especializada en Propiedad Intelectual analizó si el signo conformado por la denominación «Little Einstein Nursery School», para distinguir servicios educativos, afecta la identidad o el prestigio del científico alemán Albert Einstein. En la referida resolución, se indicó lo siguiente:

Al respecto, se considera que, si bien el signo solicitado será identificado con el reputado científico alemán Albert Einstein, tratándose de servicios educativos que implican la enseñanza y la difusión de conocimientos, no existiría una afectación a la identidad ni prestigio de dicho personaje.

[...] 
En consecuencia, debido a que el signo solicitado no afectará la identidad ni el prestigio de Albert Einstein, no es necesario solicitar el consentimiento de los herederos de dicho personaje, motivo por el cual, en el presente caso, el signo solicitado no se encuentra en la causal de prohibición establecida en el artículo 136 inciso e) de la Decisión 486, correspondiendo acceder al registro.

En general, el objeto de proteger la identidad personal es el de salvaguardar los rasgos particulares de la personalidad, que son los que diferencian plenamente a alguien del resto de personas y que le permite un reconocimiento como un ser único e irrepetible. El mercado es un escenario sin fronteras y el uso de un elemento de identificación personal podría generar serios daños a los rasgos de la identidad de una persona. Evitarlo es uno de los fundamentos de la prohibición de registro analizada.

\section{Afectación al prestigio}

El prestigio se materializa con el reconocimiento público que recibe una persona por haber desempeñado alguna actividad en forma exitosa. Muchas veces el prestigio de una persona es la principal fuente de valor de un negocio, lo que puede suceder con relación a cualquier profesión, arte u oficio. Para que un cirujano plástico, un chef o un compositor musical alcancen prestigio en sus sectores pertinentes, será el público que forma parte de esos sectores el que otorgará valor al trabajo de estas personas y un reconocimiento que las distinguirá en los campos de la medicina estética, cocina o la música, respectivamente, lo cual será determinante para la decisión del público.

Según Fernández-Nóvoa, el goodwill o buena fama se representa en la preferencia que los consumidores han otorgado a los productos o servicios distinguidos con la marca y entraña la expectativa razonable de que un producto o servicio será reiteradamente adquirido o contratado porque cuenta con el favor del público ${ }^{31}$. Por ello, el prestigio se materializa en un reconocimiento especial que el público convierte en un motivo muy sólido para direccionar sus preferencias.

31 Fernández-Nóvoa, Tratado sobre Derecho de marcas, 76. 
Un caso referido al análisis de la afectación al prestigio puede encontrarse en la Resolución 78698, del 20 de diciembre de 2012, emitida en segunda instancia por la Superintendencia de Industria y Comercio de Colombia, con respecto al nombre del famoso pintor colombiano Fernando Botero, la cual precisó lo siguiente:

En el presente caso, es evidente que esta entidad no puede desconocer la posibilidad de que en Colombia y en el mundo puedan existir varias personas que compartan el nombre "FERNANDO" y el apellido "BOTERO", pero en el presente caso el uso conjunto de FERNANDO BOTERO, sí resulta ser el nombre de un artista ampliamente reconocido en nuestro país y en el extranjero.

Entonces, al encontrarse que dicho artista goza de un amplio grado de reputación en los medios nacionales e internacionales, tema que no es objeto de discusión en el escrito de alzada, y que el instrumento por el cual se identifica ante el público es precisamente el nombre FERNANDO BOTERO, la confrontación que se haga entre este y el signo solicitado debe hacerse con mayor rigor. [...]

En este sentido, una marca destinada a identificar "bebidas alcohólicas (con excepción de las cervezas)", mediante una configuración como FERNANDO BOTERO, evidentemente se estaría aprovechando del prestigio del artista colombiano FERNANDO BOTERO, puesto que crearía la idea errónea de que la comercialización de los bienes identificados por el signo gozan de licenciamiento o aprobación en lo que respecta al uso de su imagen, cuando ciertamente está obrando sin autorización del reconocido artista.

Como se desprende, resultaría sumamente beneficioso que un empresario recurra al prestigio de una persona reconocida, en la medida en que se trata de una fuerte herramienta de diferenciación que podrá determinar la decisión de consumo por parte del público. Esta práctica per se no es ilícita, debido a que la propia ley permite que el titular autorice el uso de sus elementos de identificación; sin embargo, pretender incorporar estos elementos en una marca, sin la autorización respectiva, representaría un aprovechamiento indebido del prestigio ganado por el personaje.

Al analizar la afectación a la identidad, se precisó que los elementos incorporados en el signo debían ser suficientes para identificar a una persona determinada, independientemente de si se trata del nombre completo, el apellido, un seudónimo, etc. En el caso del prestigio sucede lo mismo: no es necesario que la persona sea reconocida con su nombre real, ya que no es extraño 
ver que muchos artistas utilizan nombres ficticios, a través de los cuales el público los identifica plenamente.

La Comisión de Signos Distintivos, al analizar el uso de un seudónimo como elemento de identificación, emitió la Resolución 5101-2019/CSD-INDECOPI, que contiene un pronunciamiento respecto al uso de la denominación «Bartola» por parte de la cantante Adriana Esther Dávila Cossio y el beneficio que podría obtenerse con el uso no autorizado de dicha denominación. La referida Comisión denegó el registro solicitado por un tercero, indicando como parte de sus fundamentos el análisis que se aprecia a continuación:

... la denominación Bartola corresponde al seudónimo de la conocida cantante de música criolla Adriana Esther Dávila Cossio, quien suele brindar diversos conciertos o presentaciones en peñas de nuestro país.

Ahora bien, conforme se aprecia, la denominación ESTD BARTOLA 2019 RESTAURANTE del signo solicitado, contiene en su conformación el término BARTOLA, el cual constituye el seudónimo de la referida cantante de música criolla, quien no ha autorizado al solicitante a registrar un elemento idéntico a su seudónimo como marca; siendo que de otorgarse el presente registro, ello afectaría la identidad y el prestigio de la citada artista musical, dado que el consumidor podría creer de manera errónea que los servicios de restauración (alimentación) de la clase 43 de la Clasificación Internacional, que pretende distinguir el signo solicitado, están asociados o relacionados con la conocida cantante de música criolla Bartola; siendo el caso que dicha artista brinda conciertos o presentaciones en peñas, donde también de forma complementaria se suelen brindar servicios de restauración.

Asimismo, debido a un amplio reconocimiento público, una persona podría ser identificada únicamente con su apellido y en ciertos casos incluso solo con su prenombre, tal y como se pudo ver en párrafos previos, al describir el caso del chef peruano Gastón Acurio. De esa forma, existen personas para las cuales, dado el éxito de sus actividades, el reconocimiento no se restringe a un sector en específico, sino que puede ser transversal a casi todos los sectores del mercado, logrando que el reconocimiento sea parte de la información que se asume como generalmente conocida.

Para finalizar, debe tomarse en cuenta que la prohibición constituye también un resguardo para el público, ya que podría generarse una asociación indebida entre un producto o servicio con el prestigio de una persona famosa en el sector correspondiente, la cual no ha autorizado el uso de ninguno de 
sus elementos de identificación. Dicha asociación conduciría a una falsa expectativa que no solo perjudicaría al público, sino también a la persona titular del prestigio, puesto que este se reduciría debido a la experiencia negativa que pueda surgir a causa de la adquisición del producto o contratación del servicio.

\section{Algunas preguntas en relación con las autorizaciones para el uso de elementos de identificación personal en marcas}

¿Si varias personas comparten los elementos de identificación (homonimia) bastará la autorización de cualquiera de ellas para registrar dichos elementos como marca? No. Para que alcance relevancia una autorización que permita la inclusión de elementos de identificación personal, su emisor debe contar con un nivel de reconocimiento o notoriedad que lo individualice fehacientemente ante el resto de las personas, a fin de que el prestigio derivado de ese reconocimiento justifique la asignación de un derecho de propiedad industrial a través del otorgamiento del registro de una marca.

¿Qué sucede si el titular del nombre decide revocar la autorización luego de concedido el registro de la marca?

Nuestra legislación no contiene una disposición que determine la pérdida del derecho sobre una marca constituida por el nombre de una persona, como consecuencia de que el titular del nombre revoque la autorización luego de concedido el registro de la marca. Si este registro fue concedido en virtud de la presentación de la autorización para el uso del nombre del personaje, no será posible aplicar la prohibición del inciso e) del artículo 136 de la Decisión 486 como causal de nulidad.

Sin perjuicio de ello, corresponde señalar que podrían existir acciones que involucren cuestiones contractuales provenientes de la autorización de uso del nombre, pero ello resultará ajeno al análisis marcario. Además, debe recordarse que la autorización únicamente puede versar sobre el contenido patrimonial o económico de la explotación del elemento de identificación de la persona reconocida, más no sobre el derecho fundamental a la identidad.

¿Qué sucede si el examinador de la solicitud de registro no reconoce a una persona famosa cuyos elementos de identificación se han incorporado en la marca? 
Ciertamente, un inconveniente podría surgir cuando la persona potencialmente afectada no formula oposición y no es reconocida por el examinador de la solicitud. En este caso, es probable que se conceda el registro y no se cuestione la inclusión del elemento que estaría afectando la identidad o el prestigio del tercero. Sin embargo, de configurarse este supuesto, aún queda expedita la acción de nulidad, que, cuando tiene como sustento una prohibición relativa (afectación de derechos de terceros) — como la del inciso e) del artículo 136 de la Decisión 486-, prescribe a los cinco años de otorgado el registro.

¿Quiénes son considerados herederos con capacidad para otorgar la autorización de uso del nombre de un personaje famoso en caso de que este haya fallecido?

La prohibición señala que, en caso de fallecimiento del titular, serán los herederos legalmente reconocidos quienes podrán autorizar el uso del nombre. Ahora bien, ante una situación en la que el titular del nombre no tenga herederos testamentarios o legales, o bien los herederos reconocidos han fallecido también, no sería posible emitir la autorización. A diferencia de la protección del derecho patrimonial de autor o de la perpetuidad del derecho moral, en este caso la ley no precisa a cuánto se extiende el tiempo de protección del nombre, por lo que este derecho se mantendrá vigente mientras su titular o sus herederos estén vivos.

Al respecto, la Comisión de Signos Distintivos, al emitir la Resolución 1701-2017/CSD-INDECOPI, analizó el requerimiento de autorización de uso de elementos de identificación, señalando lo siguiente:

... el espíritu de la norma analizada no es el de extender ad infinitum la restricción de uso del nombre o derechos de imagen de las personas y de mantener la exigencia de solicitar el consentimiento del titular del derecho de imagen para registrar algunas de sus manifestaciones como marca, sino que por el contrario, la exigencia de solicitar autorización solo se mantiene en tanto pueda recabarse del titular del derecho de imagen o de los herederos debidamente declarados del titular del derecho, lo que excluye a los descendientes posteriores, quienes ya no tienen la calidad de ser herederos declarados del titular del derecho o causante original.

Conforme a lo señalado, no debe confundirse la condición de heredero - que es la que se exige para emitir la autorización ante la muerte de la persona- con la de ascendiente o descendiente, ya que los primeros son aquellos 
indicados en el testamento en favor de quienes la persona dispone de sus bienes o, ante falta de testamento, a quienes la ley otorgue esa condición. Por su parte, los ascendientes o descendientes se determinan en función de las generaciones sucesivas de una persona en forma ascendente o descendente, de modo tal que podrán existir herederos que no son ascendientes o descendientes, así como que estos últimos podrían no tener la condición de herederos.

\section{Conclusiones}

El derecho a la identidad es un derecho fundamental que desde el plano marcario no se verá afectado si es que se permite el registro de una marca que contenga elementos de identificación que no conduzcan a la individualización de un tercero.

De esa manera, la prohibición de registro al que se refiere el inciso e) del artículo 136 de la Decisión 486 deberá aplicarse cuando el elemento utilizado en la marca conduzca a la identificación plena del afectado, a fin de salvaguardar los rasgos particulares de su personalidad, lo que permitirá, además, resguardar los intereses del público frente a una indebida asociación entre un producto o servicio del mercado y la identidad o prestigio de un personaje.

Lo anterior no significa que una marca no pueda contener elementos de identificación de personas naturales; por el contrario, como se expuso en este trabajo, se trata de una práctica recurrente en el mercado que se puede apreciar en diferentes casos nacionales e internacionales, dado que la condición para que suceda este hecho es la existencia de una autorización por parte de la persona o de sus herederos.

Por otro lado, no todos los elementos utilizados para la identificación personal podrán ser relevantes para cuestionar una marca, ya que, para ello, deberá verificarse la concurrencia de los siguientes requisitos:

a) El signo debe contener un elemento que corresponda a una persona distinta del solicitante o que dichos elementos permitan al sector pertinente identificar a una persona distinta del solicitante.

b) El signo debe afectar la identidad o prestigio de la persona.

Puede ocurrir que el elemento de identificación incorporado en el signo corresponda al propio solicitante; sin embargo, este hecho no es determinante para el otorgamiento del registro. En efecto, todos los signos cuyo registro se solicita se encuentran sujetos a un examen de registrabilidad, el cual incluye 
la verificación de que no exista la afectación a derechos marcarios previos de terceros. De ese modo, a pesar de que un personaje famoso solicite el registro de una marca que contenga su nombre $u$ otro elemento que usa para identificarse, aquel será denegado si resulta confundible con un derecho marcario previo.

Finalmente, corresponde afirmar que la naturaleza jurídica de las marcas es compatible con los elementos que sirven para identificar a una persona natural, sin que esto represente una afectación al derecho fundamental a la identidad, dado que los elementos de identificación empleados en el plano civil cumplen roles diferentes cuando se involucran en el plano mercantil.

\section{Referencias}

Botana Agra, Manuel. «El registro del nombre de un tercero como marca». En Actas de Derecho Industrial 1977, 255-276. Madrid: Montecorvo, S. A., 1978.

Fernández Sessarego, Carlos. «Daño a la identidad personal». Themis 36 (1997): 245272.

Fernández-Nóvoa, Carlos. Tratado sobre derecho de marcas, $2 .{ }^{a}$ ed. Madrid: Marcial Pons, 2004.

Flaquer Riutort, Juan. «Contribución al estudio de la marca patronímica.» En Actas de Derecho Industrial $n .{ }^{\circ} 16$ 1995-1995, 245-265. Madrid: Marcial Pons, 1996.

López Gómez, Jesús Ángel. «Consideraciones sobre la homonimia en materia de signos distintivos». En Actas de Derecho Industrial 1978, 447-469. Madrid: Montecorvo, S. A., 1979.

López Gómez, Jesús Angel. «En torno a la autorización requerida para el empleo del apellido de un tercero como marca (caso Picasso). Comentario a la sentencia del Tribunal Supremo (Sala Tercera) de 18 de junio de 1985». En Actas de Derecho Industrial 1989-1990, 157-173. Madrid: Colegio Universitario de Estudios Financieros, Consejo Superior Bancario, 1990. 
Martín Villarejo, Abel. «Singularidades subjetivas en relación con los artistas. Las interpretaciones bajo seudónimo. Derecho español, cubano y comparado». En Obras inéditas, anónimas, seudónimas, póstumas y huérfanas, editado por Eduardo Gómez Serrano y otros, 137-201. Madrid: Reus, 2014.

Otamendi, Jorge. Derecho de marcas, 7. a ed. Buenos Aires: Abeledo Perrot S.A., 2010.

Ruipérez de Azcárate, Clara. El carácter distintivo de las marcas. Madrid: Reus, S.A., 2008.

Torremans, Paul. Intellectual Property Law. 8. ${ }^{\text {a }}$ ed. Oxford: Oxford University Press, 2016.

\section{Sobre el autor}

Doctorando en Derecho en la Universidad de Alicante (España), magíster en Derecho de la Empresa por la Pontificia Universidad Católica del Perú y abogado por la Universidad Nacional Federico Villarreal. Ha participado en cursos de especialización en propiedad intelectual en Corea del Sur, Inglaterra, China y Costa Rica. Coordinador legal de la Sala Especializada en Propiedad Intelectual del Instituto Nacional de Defensa de la Competencia y de la Protección de la Propiedad Intelectual (Indecopi). Profesor de Propiedad Intelectual en la Universidad ESAN y en la Escuela Nacional del Indecopi. 


\section{Anexo}

\section{Casos en los que se aplicó la prohibición}

De modo ejemplificativo y en adición a los casos citados a lo largo del presente trabajo, en el cuadro siguiente pueden apreciarse algunas solicitudes de marcas cuyo registro no prosperó. Dichas solicitudes fueron presentadas por terceros, quienes no adjuntaron la autorización correspondiente para incluir los elementos de identificación como marca de los personajes involucrados. Como se podrá apreciar, en todos los casos resulta incuestionable la identificación de la persona afectada.

\begin{tabular}{|c|c|c|c|}
\hline Expediente & Marca & Clase & $\begin{array}{l}\text { Persona } \\
\text { afectada }\end{array}$ \\
\hline 273983-2006 & 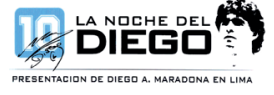 & 41 & $\begin{array}{l}\text { Diego Armando } \\
\text { Maradona }\end{array}$ \\
\hline 397461-2009 & & 28 & $\begin{array}{l}\text { Ronaldo Luis } \\
\text { Nazario de Lima }\end{array}$ \\
\hline 435001-2010 & 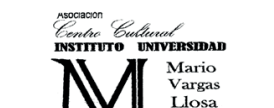 & 41 & $\begin{array}{l}\text { Mario Vargas } \\
\text { Llosa }\end{array}$ \\
\hline $543435-2013$ & MESSIGOL & 5 & Lionel Messi \\
\hline $545542-2013$ & CAFÉ PELÉ & 30 & $\begin{array}{l}\text { Edson Arantes } \\
\text { Do Nascimento }\end{array}$ \\
\hline 705407-2017 & $\begin{array}{c}\text { () Cubiertos } \\
\text { Gastón } \\
0 \\
0\end{array}$ & 8 & Gastón Acurio \\
\hline 827598-2019 & .74 & 25 & Mesut Özil \\
\hline
\end{tabular}

